\title{
VACCINE-INDUCED DEVELOPMENTAL DELAY: A CASE REPORT
}

\author{
KEERTHANA CHANDRASEKAR, TENZIN TSUNDUE, PONNUSANKAR S*
}

Department of Pharmacy Practice, JSS College of Pharmacy, Udhagamandalam - 643001, The Nilgiris, Tamil Nadu, JSS Academy of Higher Education and Research, Mysuru, Karnataka, India. Email: ponnusankarsivas@gmail.com

Received: 13 March 2018, Revised and Accepted: 30 August 2018

\section{ABSTRACT}

Vaccines are weakened or dead microbes injected for the development of an acquired immunity as a preventive measure, also including the use of microbial proteins. The spectrum of adverse events following vaccination has been increasing as well with increasing number of reports detailing the events following immunization. The rate of morbidity and mortality of many communicable diseases has significantly decreased with time with relieve to the quality of life as well as the overall pharma economic cost. In this case report vaccine-induced developmental delay was observed in a child of 16 months of age. The child was born with low birth weight despite which the child was administered with hepatitis B vaccine, poliomyelitis vaccine, and bacillus Calmette-Guerin within $24 \mathrm{~h}$ of birth. Consecutive clinical outcomes followed throughout the years, which induced a developmental delay in this child. This case clearly signifies the need for more evidence-based implementation for the management of various diseases at secondary care hospitals.

Keywords: Developmental delay, Febrile seizure, Vaccination, Bacillus Calmette-Guerin, Oral polio vaccine, Hepatitis-B.

(C) 2019 The Authors. Published by Innovare Academic Sciences Pvt Ltd. This is an open access article under the CC BY license (http://creativecommons. org/licenses/by/4. 0/) DOI: http://dx.doi.org/10.22159/ajpcr.2019.v12i1.25900

\section{INTRODUCTION}

An adverse drug event can be defined as an injury occurring resultant to a drug. In addition, it includes medication errors, adverse drug reactions, allergic reactions, and overdoses [1,2]. Vaccine-induced adverse events usually constitute of anaphylactic reactions and most commonly fever which may result into febrile seizures [3].

A febrile seizure can be defined as a seizure associated with fever resultant above $100.4^{\circ} \mathrm{F}$. The prevalence is higher in children aged between 6 months and 5 years, with most of the seizures occurring between 14 and 18 months of age [4]. Recent evidence suggests an increased risk for febrile seizures after vaccinations such as mumps measles rubella and mumps measles rubella varicella and hepatitis B vaccine (HBV) [5]. Usually, febrile seizures resolve once the child reaches the age of 6 years. However, in subjects with positive family history, they may go on to have febrile seizures well beyond this age, even into adult life. This may not necessarily be associated with high temperature, leading to generalized tonic-clonic seizures [4]. A generalized tonicclonic seizure may attribute for further neurological damage usually affecting the entire brain [6]. The etiologies and pathophysiology may vary depending on the patient and the risk factors (head trauma, central nervous system infections, febrile seizures, developmental history, and medications/toxin exposures) [7]. Recent studies reported that genetic or structural defects are the underlying causes of seizures, which may be activated after vaccination presumably due to the interplay of the innate biology of the body [8].

The latest trends in vaccine safety include that of world health organization. Adverse events following immunization (AEFI) is classified into four categories, namely program-related, vaccineinduced, coincidental, and unknown, where program-related AEFI attribute mostly to the errors in the vaccine itself, dosage forms, and route of administration. Vaccine induced AEFI occurs due to either the effects of vaccine or one of its components or may be due some underlying medical conditions or because of an idiosyncratic reaction.

Anaphylaxis reactions are rare, and the onset of anaphylaxis may occur within minutes with an unpredictable clinical course [9]. In this case report, we present a vaccine-induced developmental delay.

\section{CASE REPORT}

A 2-years-old male child presented with complaints of cough since 2 days, and with a history of breathing difficulty. The child weighed about $10 \mathrm{~kg}$ and while on examination, the vitals are pulse rate at 116 beats per min, respiratory rate at 36 per min. He was found to be afebrile and cardiovascular system with $\mathrm{S} 1$ and $\mathrm{S} 2+$, with positive bilateral air entry, however, with bilateral crept being present in the respiratory system. The child was diagnosed as wheeze associated with lower respiratory tract infection.

On assessing the medical history of the patient, the child was normally delivered with no defects and with no history of familial deformities.

The patient was found to be a known case of generalized tonic-clonic seizures, delayed development and wheeze associated with lower respiratory tract infection was diagnosed since the past 2 weeks. $\mathrm{He}$ was treated with injection ampicillin $250 \mathrm{mg}$ intravenous twice daily, injection gentamicin $20 \mathrm{mg}$ Intravenous twice daily, syrup paracetamol $50 \mathrm{ml}(25 \mathrm{mg} / \mathrm{ml})$, tablet salbutamol $1 / 4$ of $4 \mathrm{mg} 3$ times a day, salbutamol nebulization 3 times a day, and tablet chlorpheniramine maleate $1 / 4-0-1 / 4$ and was discharged with tablet amoxicillin $125 \mathrm{mg}$ 3 times a day for 7 days, tablet zinc $1 / 2(10 \mathrm{mg})$ once daily for 5 days followed by tablet chlorpheniramine maleate $1 \mathrm{mg}$ twice daily for 3 days.

Assessing further history, it was noted that the child was given HBV, poliomyelitis vaccine (PMV), and bacillus Calmette-Guerin (BCG) within $12 \mathrm{~h}$ of birth following which the child developed fever, which was symptomatically controlled. For this, the child got admitted in the neonatal intensive care unit where he developed febrile seizure and was prescribed with tablet sodium valproate $200 \mathrm{mg}$ once daily and tablet clonazepam $0.25 \mathrm{mg}$ twice daily.

At present, the child was found to be afebrile, yet irritable. He was well hydrated, and despite normal cardiovascular sounds, creps were positive for the respiratory system. Respiratory rate was found at 48 beats/min with $84 \% \mathrm{SpO}_{2}$ in room air. On the physical assessments, it was quite evident that the child has a developmental delay. He was not able to utter words and not even able to walk like other children of his age. 
The laboratory results suggested anemia with hemoglobin $9.7 \mathrm{~g} / \mathrm{dL}$, hematocrit $31.2 \%$, mean cell volume $64.9 \mathrm{~m}^{3}$, and mean cell hemoglobin at $20.2 \mathrm{pg} / \mathrm{cell}$. The total count was also elevated at $12.8 \times 10^{3} \mathrm{cells} / \mathrm{mm}^{3}$, which indicates infection. The treatment given was as follows, oxygen through face mask at the rate of $5 \mathrm{~L} / \mathrm{min}$, injection hydrocortisone $50 \mathrm{mg}$ intravenous twice daily, salbutamol nebulizer for 20 min 3 times a day, injection cefotaxime $500 \mathrm{mg}$ intravenous 3 times a day, injection ranitidine $10 \mathrm{mg}$ intravenous twice daily, tablet sodium valproate $200 \mathrm{mg}$ once daily, and tablet clonazepam $0.25 \mathrm{mg}$ twice daily.

On the $2^{\text {nd }}$ day, bilateral creps were positive, with pulse rate at 122 beats $/ \mathrm{min}$, respiratory rate at 30 beats $/ \mathrm{min}$ and $89 \% \mathrm{SpO}_{2}$. Treatment was followed as injection hydrocortisone $50 \mathrm{mg}$ intravenous twice daily, salbutamol nebulizer Q8H, injection cefotaxime $500 \mathrm{mg}$ intravenous thrice daily, injection ranitidine $10 \mathrm{mg}$ intravenous twice daily, tablet sodium valproate $200 \mathrm{mg}$ once daily, and tablet clonazepam $0.25 \mathrm{mg}$ twice daily. On the $3^{\text {rd }}$ day, the patient presented with complaints of a cough. Injection hydrocortisone was stopped and followed by adding tablet prednisolone $5 \mathrm{mg}$ and tablet azithromycin $250 \mathrm{mg} 1 / 2$ once daily to the therapy. The patient was discharged on the $4^{\text {th }}$ day with tablet sodium valproate $200 \mathrm{mg}$ once daily, tablet clonazepam $0.25 \mathrm{mg}$ twice daily, tablet azithromycin $250 \mathrm{mg} 1 / 2$ once daily for 4 days, tablet cetirizine $5 \mathrm{mg} 1 / 2$ at night time for 4 days, tablet salbutamol $1 / 2$ at hour of sleep for 4 days, and Budecort 100 mcg 1 puff twice daily for 3 months.

\section{DISCUSSION}

With an increasing number of infectious diseases as well as resistant strains, the need for a preventive strategy is a must [10]. However, apart from these active constituents, the vaccine contains one or more of excipients, and once the vaccine enters one's fluid system, a cascade of immunological responses takes place. This pathway defines ones intrinsic reactions to the vaccine for the outcome of a proper response or an anaphylactic reaction [11].

In this case report, the patient despite with low birth weight was given $\mathrm{BCG}$, oral polio vaccine, and HBV within $24 \mathrm{~h}$ of birth. A question that arises now is the ultimate fate of the immune system and the biological pathways in low birth weight children. The excipients content of the HBV was aluminum hydroxide gel $0.25 \mathrm{mg}$, thiomersal $0.025 \mathrm{mg}$, and phosphate buffer. BCG vaccine being constituted in sodium chloride $1 \mathrm{ml}$ $0.9 \% \mathrm{w} / \mathrm{v}$ and PMV contains kanamycin $20 \mathrm{mcg}$ as a preservative. This brings to light the thiomersal controversy, the removal of thiomersal from vaccines in the United States of America since 2001. Where, once evidence suggested the association between thiomersal and autism while some of the other evidence not supporting the same [12]. However, considering the risk verses benefit, ensuring thiomersal is really associated or not associated to neurological deformities is still controversial. Further requires more evidences and justification.

Furthermore, current recommendations state the need for scheduled vaccinations in preterm and children born with low birth weight [13]. However, this recommendation is feasible only if the child is clinically stable. Quite contrarily, the debate lies in the doses of the vaccine given at the time of birth, that is, HBV and BCG. Still, the implementation of these is restricted in most countries due to the concerns of parents and the health-care providers regarding the biology of immunogenicity and safety of vaccines in these populations [14]. However, the conclusiveness of these finding is a big question keeping in mind the scarcity of evidence in this field. In this case report, the child despite born with low birth weight was given three vaccinations as mentioned above and sequentially developed fever post-vaccination resultant into a febrile seizure. Recurrent febrile seizures led to generalized tonic-clonic seizures not associated with fever. The child suffers from the developmental delay at present. Recent data suggest the interplay of plasma multiplex cytokines and increased level of interleukin-10 and interleukin-1 receptor antagonist as an etiological factor for conversion of febrile seizures into non-febrile seizure [15].
The laboratory values indicated a decreased value of hemoglobin, hematocrit, mean cell volume, mean cell hemoglobin, and a increased value in total white cell count. The treatment that followed indicated for supportive and symptomatic relief. Preventive therapy was initiated later only with an inhaled corticosteroid. Irrational use of antibiotics and corticosteroids was observed in this case, however, with guidelines suggesting antibiotic therapy first-line therapy being the macrolides or amoxicillin followed by preventive measure with inhaled corticosteroids [16].

The long-term use of sodium valproate carries an enormous risk of hepatotoxicity; however, no laboratory tests were done regarding the hepatic abnormality and the laboratory test done was yet not sufficient to rule out many of the complications. In such cases, there is an enormous need of diagnostic protocols [17]. However, in this present scenario, prolonged therapy with sodium valproate yielded acceptable outcome, though the use of add-on therapy with clonazepam indicates the lack of guideline implementation. Laboratory findings and interpretations are necessary in such cases to rule out any forms of complications that need to be addressed.

In addition, it was quite evident the child had a developmental delay (Fig. 1). Developmental delays and autism can be a consequence of vaccine-induced adverse events where the developmental delay is a neurological disorder with huge impact on the quality of life of the patient [18]. Furthermore, the possible association between vaccination and developmental disorders has been subject of great debate resultant doubts and anxiety in the parents seeking the best for their child [19].

This case clearly demonstrates the lack of guideline implementation in the management of respiratory and neurological diseases and furthermore the scarcity of evidence in the sequential vaccination in low birth weight child.

\section{CONCLUSION}

This case clearly signifies the need for more evidence-based implementation for the management of various diseases at secondary level hospitals. In addition, further studies are needed to demonstrate the impact of vaccination schedules based on the birth weight of the child and whether thiomersal-containing vaccines should be administered or not. Conclusive guidelines and updated knowledge for physicians are a need of the hour, resultant less incidences of health burden to the general population.

\section{AUTHORS' CONTRIBUTION}

Keerthana Chandrasekar-involved in the collection of this case report during the ward rounds and made follow-up of the patient. Tenzin

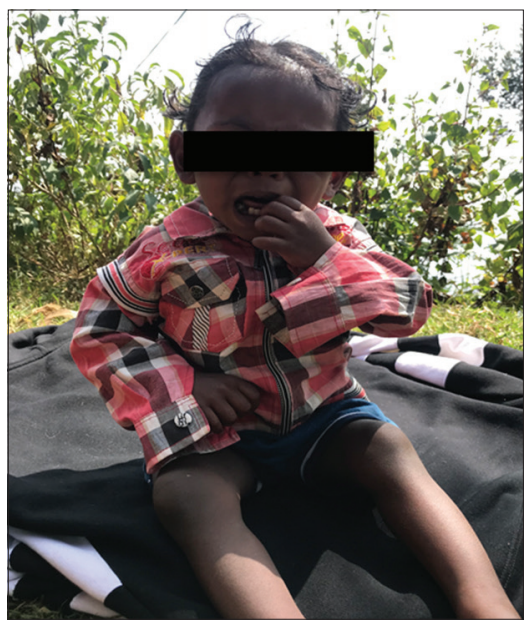

Fig. 1: Delayed development in the child 
Tsundue-involved in the pharmacotherapeutic discussion was conducted and follow-up of the patient. S Ponnusankar - has provided the design to write the case report and summarizing the write-up of the case.

\section{CONFLICTS OF INTEREST}

The authors do not report any conflicts of interest

\section{ACKNOWLEDGMENT}

The authors acknowledge the support and cooperation provided by JSS College of Pharmacy, Ooty.

\section{REFERENCES}

1. Kohn LT, Corrigan JM, Donaldson MS. To Err is Human: Building a Safer Health System. Washington, DC: National Academy Press; 2000.

2. Mishra A, Manideep R, Adepu R, Mothi SN, Swamy VH. Induced Stevens-Johnson syndrome in a human immunodeficiency virus patient: A case report. Asian J Pharm Clin Res 2016;9:1-2.

3. Staltari O, Cilurzo F, Caroleo B, Greco A, Corasaniti F, Genovesi MA, et al. Annual report on adverse events related with vaccines use in Calabria (Italy): 2012. J Pharmacol Pharmacother 2013;4:S61-5.

4. Chung S. Febrile seizures. Korean J Pediatr 2014;57:384-95.

5. Stratton K, Ford A, Rusch E, Clayton EW. Review Adverse Effects of Vaccines. Institute of Medicine. Washington (DC): National Academies Press (U S); 2011

6. Upadhyay J, Upadhyay G, Rana AM. A prospective study on prevalence of epilepsy disorders and drug utilization pattern. Asian J Pharm Clin Res 2017;10:136-9.

7. Gencpinara P, Yavuzb H, Bozkurtc O, Haspolatc S, Dumanc O. The risk of subsequent epilepsy in children with febrile seizure after 5 years of age. Seizure 2017;53:62-5

8. Verbeek NE, Jansen FE, Vermeer-de Bondt PE, Kovel CG, Kempen MJ, Lindhout $\mathrm{D}$, et al. Etiologies for seizures around the time of vaccination. Pediatrics 2014;134:658-66.

9. Vaccine safety and adverse events following immunisation. Green Book. Vol. 4. Ch. 8. Washington, DC: Public Health England; 2013.

10. Schuchat A, Anderson LJ, Rodewald LE, Messonnier NE, Jernigan DB, Wharton M. Progress in vaccine-preventable and respiratory infectious diseases-first 10 years of the CDC national center for immunization and respiratory diseases, 2006-2015. Emerg Infect Dis 2018;24:1178-87.

11. Ward BJ. Vaccine adverse events in the new millennium: Is there reason for concern? Bull World Health Organ 2000;78:205-15.

12. Centers for Disease Control and Prevention. National Center for Emerging and Zoonotic Infectious Diseases (NCEZID). Division of Healthcare Quality Promotion (DHQP); 2015.

13. Ochoa TJ, Zea-Vera A, Bautista R, Davila C, Salazar JA, Bazan C, et al. Vaccine schedule compliance among very low birth weight infants in Lima, Peru. Vaccine 2015;33:354-8.

14. Ventola CL. Immunization in the United States: Recommendations, barriers, and measures to improve compliance: Part 2: Adult vaccinations. P T 2016;41:492-506.

15. Kim K, Kwak BO, Kwon A, Ha J, Kim SJ, Bae SW, et al. Analysis of plasma multiplex cytokines and increased level of IL-10 and IL-1Ra cytokines in febrile seizures. J Neuroinflammation 2017;14:200.

16. Global Initiative for Asthma. Pocket Guide for Health Professionals Updated; 2017.

17. Powell-Jackson PR, Tredger JM, Williams R. Hepatotoxicity to sodium valproate: A review. Gut 1984;25:673-81.

18. Dorling J, Salt A. Evidence based case report: Assessing developmental delay. BMJ 2001;323:148-9.

19. Roberts W, Harford M. Immunization and children at risk for autism. Paediatr Child Health 2002;7:623-32. 